\title{
Comparative Study of Anthropometric Measurement and Body Composition between the Basketball Player First and Second League in Montenegro
}

\author{
Velisa Vukasevic', Spasoje Spaic², Bojan Masanovic² \\ 'Basketball Club Vizura, Belgrade, Serbia, ${ }^{2}$ University of Montenegro, Faculty for Sport and Physical Education, Niksic, Montenegro
}

\begin{abstract}
The purpose of this study was to describe morphological characteristics and body composition of the basketball players from First and Second League in Montenegro as well as to make comparation between them. Forty-eight males were enrolled in the study, divided into two groups: twenty-four senior players from the First Basketball League and twenty-four senior players from the Second Basketball League of Montenegro. Morphological characteristics were evaluated by a battery of four variables: body height, body weight, arm span and length of the leg. Body composition were evaluated by a battery of two variables: Body mass index and fat percentage of body. The standard central and dispersive parameters of all variables were calculated. The significance of the differences between the basketball players from First and Second League in Montenegro was determined by a t-test for small independent samples. The purpose of this study is to describe the anthropometric characteristics and the body composition of the basketball player, and to determine possible differences in relation to the ranking of the competition. The results showed that a significant differences was no found for any variable among the group. Therefore, these findings may give coaches knowledge that no significant difference between the level of competition.
\end{abstract}

Key words: Basketball, Morphological Characteristics, Body Composition, Montenegro

\section{Uvod}

Košarka kao sportska aktivnost je kroz svoju dugogodišnju istoriju doživjela evoluciju od alternativne igre do visoko selektivne sportske grane u kojoj je uspjeh rezervisan isključivo za najtalentovanije i najsposobnije pojedince (Vukasevic, 2010). U početnoj fazi pojavljivanja bila je namijenjena i dostupna širokom spektru zainteresovanih, što je dovelo do nevjerovatno brze ekspanzije i popularnosti širom svijeta.

Postoji veliki spektar motiva za uključivanje pojedinca u aktivno ili rekreativno bavljenje košarkom, kao sportskom aktivnošću, koje je uslovljeno brojnim željama i potrebama samog korisnika. Na osnovu socijalnih, individualnih i društve- nih potreba, željenih nivoa sportske aktivnosti, vrijednosne ljestvice i vidova angažovanja u sportu, možemo razlikovati nekoliko osnovnih vrsta konzumacije sporta: razvojni sport, rekreativni sport, standardni sport, vrhunski sport (Havelka \& Lazarević, 1981). Razvojni sport je koncipiran tako da se realizuje u praksi fizičkog vaspitanja, gdje su učesnici djeca i omladina, sa osnovnim ciljem ostvarivanja zadataka fizičkog vježbanja (Bjelica, i Krivokapic, 2011; Bjelica 2002; Bjelica, 2005). Rekreativni sport u najvećoj mjeri okuplja pojedince usmjerene ka održavanju psihofizičkih sposobnosti na optimalnom nivou, a karakteriše ga slobodan izbor fizičke aktivnosti, praćen pravilnom pedagoškom i medicinskom kontro-

Correspondence:

Montenegro B. Masanovic

Sport University of Montenegro, Faculty for Sport and Physical Education, Narodne omladine bb, 81400 Niksic, Montenegro E-mail: bojanma@ac.me 
lom (Bjelica, 2006a; Bjelica 2006b). Standardni sport se ogleda u masovnosti recepijenata i širokoj rasprostranjenosti u svakoj životnoj sredini (Vukasevic, 2010). Vrhunski sport se definiše kao aktivnost usmjerena na postizanje najvećih sportskih dostignuća, gdje je osnovna mjerna jedinica uspjeha, upravo sportski rezultat (Havelka \& Lazarević, 1981; Bjelica i Krivokapic, 2010; Bjelica i Krivokapic, 2012). Usmjerenost ka najvećim sportskim rezultatima i profesionalnom bavljenu košarkom, u velikoj mjeri zavisi od pravovremenog selektiranja igrača (Masanovic, 2008; Masanovic, 2009; Masanovic, Popovic, \& Molnar, 2009; Popovic, Masanovic, Molnar, \& Smajic, 2009, Popovic, Molnar, \& Masanovic, 2010). Identifikovanje talenata i efikasno sprovođenje transformacijsko kinezioloških aktivnosti predstavlja osnovnu fazu u procesu programiranja, planiranja i realizacije trenažnog procesa, koje se u najvećoj mjeri bazira na rezultatima sportske nauke i prakse (Bjelica, Popovic, \& Gardasevic, 2016a; Bjelica, Popovic, \& Gardasevic, 2016a; Masanovic, Popovic, \& Bjelica, 2018). Kriterijumi selekcije, multidisciplinarno postavljeni, u potpunosti pokrivaju cjelokupni antropološki status košarkaša (Vukotic, 2010; Vukotic, 2011).

Antropometrijske karakteristike i tjelesni sastav košarkaša imaju veoma značajnu ulogu kako u selekciji kod mlađih kategorija - pionira, kadeta i juniora, tako i u igračkom kvalitetu u seniorskoj konkurenciji (Carter \& Heath, 1990; Popovic, Smajic, Joksimovic, \& Masanovic, 2010; Bjelica, Gardaevic, \& Vasiljevic, 2018). Utvrđeno je da morfološku strukturu košarkaša odlikuje izrazita tjelesna visina i dugi ekstremiteti, a da količina potkožnog masnog tkiva negativno deluje na efikasnost igrača i ograničava njihove motoričke i funkcionalne potencijale (Popovic, Akpinar, Jaksic, Matic, \& Bjelica, 2013; Masanovic, Vukotic, Bjelica, \& Popovic, 2018; Popovic, Bjelica, Vukotic, \& Masanovic, 2018; Vukotic, Corluka, Vasiljevic, \& Bubanja, 2018, Vukotic, 2018). Uspešan košarkaš mora posedovati određene morfološke karakteristike međusobno različite s obzirom na njegovu užu specijalnost u igri - bek, krilo, centar (Saavedra, Porgeirsson, Kristjansdottir, Halldorsson, Guðmundsdottir, \& Einarsson, 2018; Cvorovic, 2012). Na stalan rast ukupnog masnog tkiva u telu utiču genetski činioci, ali mnogo više ishrana, endokrini faktori i fizička aktivnost (Misigoj-Durakovic, Matkovic, i Medved, 1995; Nikolaidis, Vassilios-Karydis, 2011; Sermaxaj, Popovic, Bjelica, Gardasevic, \& Arifi, 2017). Sa porastom sportske pripremljenosti, smanjuje se postotak masnog tkiva (Bošnjak, Bukovala, \& Soudil, 1986). Za trenažnu tehnologiju košarkaša, informacije o strukuri morfoloških karakteristika predstavljaju veoma bitne aspekte njihove transformacije u željenom pravcu u svakom trenutku njihove karijere (Stojanovic, Calleja-Gonzalez, Mikic, Madic, Vučković, \& Ostojić, 2016; Nepocatych, Balilionis, \& O’Neal, 2017). Pod morfološkim karakteristikama antropološkog statusa čovjeka se podrazumijevaju procesi rasta i čovjekovog onogenetskog razvoja (Bjelica i Fratric, 2011; Bjelica, 2013). Razlikujemo četiri morfološka faktora: longitudianalna dimenzionalnost skeleta (rast kostiju u dužini), transverzalna dimenzionalnost (rast kostiju u širini), volumen mase i tijela (obim tijela), potkožno masno tkivo (ukupna količina masti u organizmu).

Karalejić i Jakovljević (2008) u svojoj definiciji uspješnog košarkaša kao prvi i najvažniji element navode upravo antropometrijske karakteristike. Pored ovih dimenzionalnosti, a u okviru antropometrijskih karakteristika, oni navode jos i kompoziciju tijela i somatotip igrača. Morfološka struktu- ra tijela košarkaša bazira se na interakciji svih antropoloških mjera, koje su pretežno pod uticajem genetskih, endogenih i egzogenih, odnosno faktora okoline (Vukasevic, 2010). Koeficijent urođenosti skeleta je $0,98 \%$, za voluminoznost $0,90 \%$, a za potkožno masno tkivo $0,50 \%$. Najveća moguća transformacija treningom i ostalim egzogenim uticajima moguća je kod karakteristika sa niskim stepenom urođenosti. Informacije o kvalitetu izvršenja trenažnih zadataka se u velikoj mjeri ogleda kroz antropometrijske karakteristike (Ramos-Campo et al., 2014; Masanovic \& Vukasevic, 2009). Tjelesna masa nije visoko genetski nasledna, već se trenažnim procesom može uticati na njeno redukovanje. Body-mass index (BMI) se definiše kao visinsko-težinski pokazatelj uhranjenosti pojedinca, takođe je podložan promjenama pod uticajem sportskog treninga. Matematički gledano, računa se kao količnik tjelesne mase, izražene u kilogramima i visine tijela, izražene u metrima (Strel, 2006).

Savremena današnjica omogućila nam je dostupnost mnogo znanja iz svih oblasti, sportista je doveden do visokog nivoa pripremljenosti, rekordi u pojedinim disciplinama su tako visoki da je pitanje jesu li više dostupni (Masanovic, 2015). Na najvećim sportskim smotrama učestvuje veliki broj gotovo izjednačenih sportista, nijanse između kvalietnih i vrhunskih igrača odlučuju ko će odnijeti pobjedu. Poređenje igrača koji se takmiče na različitim takmičarskim nivoima mogu da nam pomognu da shvatimo koje su to nijanse koje prave razliku i pomažu na putu do pobjede. Morfološke karakteristike košarkaša različitog kvaliteta, su od presudnog značaja u detrminisanju uspjeha vrhunskih sportista (Bjelica, 2004; Popovic, Bjelica, Jaksic, \& Hadzic, 2014; Gusic, Popovic, Molnar, Masanovic, \& Radakovic). Posmatrajući finese, izražene u samoj morfologiji košarkaša, možemo potražiti presudne faktore koji izdvajaju pojedinca, odnosno procijeniti u kojoj mjeri utiču na kvalitet i uspješnost nastupa i nadmetanja u određenom rangu takmičenja. Dakle, utvrditi odnos individualnih karakteristika, sa stepenom takmičarkog kvaliteta.

Svrha ove studije jeste opisati antropometrijske karakteristike i kompoziciju tijela košarkaša, i utvrditi moguće razlike u odnosu na rang takmičenja.

\section{Metod}

Uzorak ispitanika čini ukupno 48 košarkaša seniorskog uzrasta, podijeljen na dva subuzorka. Prvi subuzorak su činili 24 košarkaša koji nastupaju u Prvoj ligi Crne Gore, prosječne starosti $22.75 \pm 4.24$ godina, dok su drugi subuzorak činili 24 košarkaša koji nastupaju u Drugoj ligi Crne Gore, prosječne starosti $22.21 \pm 4.24$ godina.

Antropometrijsko istraživanje sprovedeno je uz poštovanje osnovnih pravila i principa vezanih za izbor mjernih instrumenata i tehnike mjerenja koji su standardizovani, prema upustvima Internacionalnog Biološkog Programa. Za potrebe ovog istraživanja izmjerene su četiri varijable morfoloških mjera: visina tijela (ATV), težina tijela (ATM), raspon ruku (ARR), dužina noge $(A D N)$, i dvije varijable za procjenu tjelesnog sastava tijela: body mass index (BMI), procenat masnog tkiva (APM). Za antropometrijsko merenje korišćeni su standardizovani mjerni instrumenti: antropometar po Martinu i vaga. Sve relevantne antropomotoričke dimenzije (osim morfološkog svojstva-raspona ruku koje je izmereno antropometrom u standardnim uslovima) su određene prema standardima internacionalnog biološkog programa. Za procjenu sastava tijela korišćena je tanita vaga, model BC-418MA. Princip 
rada ove vage je zasnovan na indirektnom mjerenju tjelesnog sastava, bezbjedan električni signal se šalje kroz tijelo preko elektroda smještenih u samostalnu jedinicu. Tanita vaga, zahvaljujući atletskom modu koje posjeduje, omogućava sportistima detaljno praćenje tjelesne težine, zdrastvenog stanja i kondicije, sa svim relevantnim parametrima.

Podaci dobijeni istraživanjem obrađeni su postupcima deskriptivne i komparativne statističke procedure. Za svaku varijablu su obrađeni centralni i disperzioni parametri kao i mjere asimetrije i spljoštenosti. Razlike u morfološkim dimenzijama i sastavu tijela košarkaša koji nastupaju u prvoj i drugoj ligi Crne Gore utvrđene su primjenom diskriminativne parametrijske procedure, t-testom za male nezavisne uzorke, sa statističkom značajnošću od $\mathrm{p}<0.05$.

\section{Rezultati}

U Tabelama 1 i 2 prikazani su osnovni deskriptivni statistički parametri antropometrijskih varijabli i tjelesnog sa-

Tabela 1. Centralni i disperzioni parametri varijabli za procjenu morfoloških karakteristika i tjelesnog sastava košarkasa prve lige Crne Gore

\begin{tabular}{|c|c|c|c|c|c|c|c|c|c|}
\hline & \multirow{2}{*}{ Min } & \multirow{2}{*}{ Max } & \multirow{2}{*}{ Mean } & \multirow{2}{*}{ Std.D. } & \multirow{2}{*}{ Variance } & \multicolumn{2}{|c|}{ Skewness } & \multicolumn{2}{|c|}{ Kurtosis } \\
\hline & & & & & & Stat. & Std. E. & Stat. & Std. E. \\
\hline ATV & 185.00 & 208.00 & 198.38 & 7.418 & 55.027 & -.425 & .472 & -1.153 & .918 \\
\hline ATM & 78.00 & 111.00 & 93.00 & 8.496 & 72.174 & .464 & .472 & -.126 & .918 \\
\hline ARR & 185.00 & 214.00 & 200.83 & 9.430 & 88.928 & -.282 & .472 & -1.559 & .918 \\
\hline ADN & 104.00 & 122.00 & 115.00 & 5.225 & 27.304 & -.680 & .472 & -.544 & .918 \\
\hline BMI & 21.00 & 26.00 & 23.67 & 1.494 & 2.232 & .117 & .472 & -1.186 & .918 \\
\hline APM & 8.00 & 16.00 & 11.62 & 2.445 & 5.984 & -.009 & .472 & -1.038 & .918 \\
\hline
\end{tabular}

Legenda: visina tijela (ATV), težina tijela (ATM), raspon ruku (ARR), dužina noge (ADN), i dvije varijable za procjenu sastava tijela: indeks tjelesne mase (BMI), procenat masti (APM).

stava košarkaša dvije najjače crnogorske lige, gdje su izračunate vrijednosti mjera centralne i disperzione tendencije i to: aritmetička sredina (Mean), standardna devijacija (Std. Dev.), varijansa (Variance), minimalne (Min) i maksimalne (Max) vrijednosti, koeficijenti zakrivljenosti (Skewness) i izduženo- sti (Kurtosis). Prvo su analizirani centralni i disperzioni parametri varijabli za procjenu morfoloških karakteristika i sastava tijela košarkaša koji nastupaju u najkvalitetnijoj ligi Crne Gore (Tabela 1.).

Na osnovu centralnih i disperzionih parametara, vrijedno-

Tabela 2. Centralni i disperzioni parametri varijabli za procjenu morfoloških karakteristika i tjelesnog sastava košarkaša druge lige Crne Gore ( $\mathrm{N}=24)$

\begin{tabular}{|c|c|c|c|c|c|c|c|c|c|}
\hline & \multirow{2}{*}{ Min } & \multirow{2}{*}{ Max } & \multirow{2}{*}{ Mean } & \multirow{2}{*}{ Std.D. } & \multirow{2}{*}{ Variance } & \multicolumn{2}{|c|}{ Skewness } & \multicolumn{2}{|c|}{ Kurtosis } \\
\hline & & & & & & Stat. & Std.E. & Stat. & Std. E. \\
\hline ATV & 182.00 & 206.00 & 194.87 & 6.842 & 46.810 & -.452 & .472 & -.735 & .918 \\
\hline ATM & 72.00 & 110.00 & 91.75 & 11.245 & 126.457 & -.122 & .472 & -.829 & .918 \\
\hline ARR & 181.00 & 212.00 & 196.42 & 8.757 & 76.688 & -.203 & .472 & -.763 & .918 \\
\hline DAN & 102.00 & 123.00 & 113.96 & 5.385 & 28.998 & -.432 & .472 & -.231 & .918 \\
\hline BMI & 22.00 & 28.00 & 24.13 & 1.597 & 2.549 & -.408 & .472 & -.098 & .918 \\
\hline APM & 8.00 & 17.00 & 12.38 & 2.618 & 6.853 & -.052 & .472 & -.986 & .918 \\
\hline
\end{tabular}

sti skjunisa i kurtozisa može se konstatovati da su sve varija- _ jer imaju pozitivan predznak, dok ostale varijable imaju imable u granicama normalne raspodjele. Vidi se po vrijednosti skjunisa da dvije varijable: tjelesna masa i BMI imaju blagu asimetriju, ne i statistički značajnu u stranu slabijih rezultata ju negativan predznak što pokazuje da su rezultati desno od srednje vrijednosti tj među većim vrijednostima. Po vrijednosti kurtozisa se vidi da sve varijable pokazuju raspodjelu pljo-

Tabela 3. Vrijednosti t-testa izmedju aritmetičkih sredina varijabli za procjenu morfoloških karakteristika i sastava tijela igrača Prve i Druge lige Crne Gore

\begin{tabular}{|c|c|c|c|c|c|c|c|}
\hline Varijable & Lige & Mean & Std. D. & Std. E.M. & t-test & Sig. & Mean Diff \\
\hline \multirow[t]{2}{*}{ ATV } & I liga & 198.38 & 7.418 & 1.514 & 1.699 & .096 & 3.500 \\
\hline & II liga & 194.88 & 6.842 & 1.397 & & & \\
\hline \multirow[t]{2}{*}{ ATM } & I liga & 93.00 & 8.496 & 1.734 & .435 & .666 & 1.250 \\
\hline & II liga & 91.75 & 11.245 & 2.295 & & & \\
\hline \multirow[t]{2}{*}{ ARR } & I liga & 200.83 & 9.430 & 1.925 & 1.681 & .099 & 4.417 \\
\hline & II liga & 196.42 & 8.757 & 1.788 & & & \\
\hline \multirow[t]{2}{*}{ ADN } & I liga & 115.00 & 5.225 & 1.067 & .680 & .500 & 1.042 \\
\hline & II liga & 113.96 & 5.385 & 1.099 & & & \\
\hline \multirow[t]{2}{*}{ BMI } & I liga & 23.67 & 1.494 & .305 & -1.027 & .310 & -.458 \\
\hline & II liga & 24.13 & 1.597 & .326 & & & \\
\hline \multirow[t]{2}{*}{ APM } & I liga & 11.63 & 2.446 & .499 & -1.026 & .310 & -.750 \\
\hline & II liga & 12.38 & 2.618 & .534 & & & \\
\hline
\end{tabular}


snatiju od normalne, tj da ima više rezultata nagomilanih na repovima raspodjele.

$\mathrm{Na}$ osnovu centralnih i disperzionih parametara, vrijednosti skjunisa i kurtozisa koji nastupaju u drugom po kvalitetu rangu takmičenja u Crnoj Gori, može se konstatovati da su sve varijable u granicama normalne raspodjele i da su vrijednosti vrlo slične košarkašima prvog po kvalitetu ranga takmičenja. Po negativnim vrijednosti skjunisa vidi se da je kod svih varijabli većina rezultata desno od srednje vrijednosti, među većim vrijednostima. Negativne vrijednosti spljoštenosti (kurtozisa) kod svih varijabli pokazuju da je raspodjela pljosnatija od normale, tj. da ima više rezultata nagomilanih na repovima raspodjele. Da bi se moglo utvrditi da li ima statistički značajne razlike $u$ analiziranim varijablama kod košarkaša ova dva ranga takmičenja, primjenjena je statistička procedura t-test (Tabela 3).

Na osnovu dobijenih vrijednosti rezultata t-testa, može se primijetiti da ne postoje statistički značajne razlike ni kod jedne varijable na nivou značajnosti $\mathrm{p}<0.05$. Može se konstatovati da komparativna analiza morfoloških karakteristika i tjelesne kompozicije ne pokazuje značajnu razliku u odnosu na rang takmičenja.

\section{Diskusija}

Guarav (2010) u svom istraživanju ukazuje da košarkaše karakteriše velika tjelesna visina, kao bitan parameter u samoj selekciji igrača, a kao osnovne razloge navodi specifičnosti same igre, visinu na kojoj se nalazi obruč i konstantnu potreba da se protivnik nadvisi. Prednost visokih igrača je mogućnost da šutiraju sa kraće distance, da imaju viši dohvat u skoku za loptom a takođe i u bloku. Ako uporedimo igrače dvije najkvalitetnije lige Crne Gore sa prvoplasiranim ekipama sa poslednjeg Evropskog prvenstva u košarci primjećujemo određenu razliku u visini koja nije statistički značajna. Prema zvaničnim podacima prosječna visina šampiona Slovenije je $199.5 \mathrm{~cm}$, dok drugoplasirana Srbija i trećeplasirana Španija u prosjeku prelaze dva metra. Ako uzmemo u obzir da su ovo najuspješnije reprezentativne selekcije, mala razlika u visini sa kosarkašima Prve crnogorske lige $(198.37 \mathrm{~cm})$, te Druge $(194.88 \mathrm{~cm})$, logična i očekivana. Na osnovu toga mežemo zaključiti da je selekcija dobro obavljena, i da sa aspekta tjelesne visine Crnogorci kao nacija mogu zadovoljiti potrebe savremene košarke, imajući u vidu da $28 \%$ ispitanika opšte populacije dostiže visinu od 190 ili više centimetara (Bjelica, Popović, Kezunović, Petković, Jurak, \& Grasgruber, 2012; Popović, Bjelica, Molnar, Jakšić, \& Akpinar, 2013; Popović, Bjelica, Tanase, i Milašinović, 2015; Popović, Bjelica, Georgijev, Krivokapić, \& Milašinović, 2017; Popovic, 2016; Popovic, 2017), što predstavlja neizostavan aspekt pri selektiranju igrača.

Cilj ovog istraživanja jeste opisati antropometrijske karakteristike i kompoziciju tijela košarkaša, i utvrditi moguće razlike u odnosu na rang takmičenja. Uzorak od ukupno 48 košarkaša seniorskog uzrasta podijeljen je na dva subuzorka. Prvi subuzorak čine 24 košarkaša Prve crnogorske lige, prosječne starosti $22.75 \pm 4.24$ godina, dok drugi čine 24 košarkaša Druge crnogorske lige, prosječne starosti $22.21 \pm 4.24$ godina. Rezultati su dobijeni posmatranjem četiri varijable za procjenu morfoloških mjera i dvije za procjenu sastava tijela.

$\mathrm{Na}$ osnovu dobijenih rezultata možemo zaključiti da ne postoje statistički značajne razlike između subuzoraka ni kod jednog izmjerenog parametra. To nam ukazuje na uspješnu selekciju i kada je u pitanju drugi po kvalitetu ranga takmičenja, što direktno govori o izjednačenosti konkurencije, odnosno kvalitetnom radu i u klubovima nižeg ranga takmičenja. Dakle, posmatrano sa stanovišta morfologije i sastava tijela, košarkaši Druge lige Crne Gore ne zaostaju za igračima Prve lige.

Rezultati koji su dobijeni ovim istraživanjem mogu poslužiti kao modelni parametri u procjenjivanim varijablama za sve ostale igrače istih rangova takmičenja u Crnoj Gori, jer su analizirani igrači članovi najkvalitetnijih timova. Treba napomenuti da grači koje žele uspješno nastupati u ligama gdje se igra najkvalitetnija košarka, moraju imati karakteristike utvrđene standardima za taj sport, a to se prije svega ogleda u morfološkim dimenzijama i tjelesnom sastavu.

\section{Acknowledgements}

There are no acknowledgements.

\section{Conflict of Interest}

The authors declare that there are no conflict of interest.

Received: 02 May 2018 | Accepted: 18 June 2018 | Published: 13 July 2018

\section{References}

Bjelica, D. (2002). Opšti pojmovi sportskog treninga: (skraćena verzija). Podgorica: Crnogorska sportska akademija.

Bjelica, D. (2004). Uticaj sportskog treninga na antropomotoričke sposobnosti: (fudbalskih kadeta Crne Gore). Podgorica: Crnogorska sportska akademija.

Bjelica, D. (2005). Sistematizacija sportskih disciplina i sportski trening. Podgorica: Crnogorska sportska akademija.

Bjelica, D. (2006a). Sportski trening. Podgorica: Crnogorska sportska akademija.

Bjelica, D. (2006b). Teorijske osnove tjelesnog i zdrastvenog obrazovanja. Podgorica: Crnogorska sportska akademija.

Bjelica, D. (2013). Teorija sportskog treninga. Podgorica: Univerzitet Crne Gore.

Bjelica, D., \& Fratrić, F. (2011). Sportski trening: teorija, metodika i dijagnostika. Nikšić: Fakultet za sport i fizičko vaspitanje.

Bjelica, D., Gardasevic, J., \& Vasiljevic, I. (2018). Differences in the morphological characteristics and body composition of football players FC Sutjeska and FC Mladost in Montenegro. Journal of Anthropology of Sport and Physical Education, 2(2), 31-5. doi: 10.26773/jaspe.180406

Bjelica, D., i Krivokapić D. (2012). Uticaj fizičkog vježbanja na psihomotorne funkcije starijih osoba. Zbornik radova Druge međunarodne konferencije Sportske nauke izdravlje, Banja Luka: Panaevropski univerzitet APEIRON, 191-6.

Bjelica, D., i Krivokapić, D. (2010). Teorijske osnove fizičke kulture. Nikšić: Fakultet za sport i fizičko vaspitanje Univerziteta Crne Gore.

Bjelica, D., i Krivokapić, D. (2011). Teorija igre. Nikšić: Fakultet za sport i fizičko vaspitanje Univerziteta Crne Gore.

Bjelica, D., Popović, S., i Gardašević, J. (2016a). Modeli fizičke pripreme vrhunskih sportaša i doziranje opterećenja. Zbornik radova 14. godišnje međunarodne konferencije "Kondicijska priprema sportaša" (185-189), Zagreb: Udruga kondicijskih trenera Hrvatske.

Bjelica, D., Popović, S., i Gardašević, J. (2016b). Opći principi planiranja i programiranja fizičkih priprema sportaša. Zbornik radova 14. godišnje međunarodne konferencije "Kondicijska priprema sportaša" (190-192), Zagreb: Udruga kondicijskih trenera Hrvatske.

Bjelica, D., Popović, S., Kezunović, M., Petković, J., Jurak, G., \& Grasgruber, P. (2012). Body Height and Its Estimation Utilizing Arm Span Measurements in Montenegrin Adults Anthropological Notebooks, 18(2), 69-83.

Bošnjak, V., Bukovala, P., Soudil, J. (1985). Morfološke karakteristike košarkaša odreðene metodom Mateigka. Beograd: SMG

Carter, J.E.L., \& Heath, B.H. (1990). Somatotyping-Development and application. Cambridge, United Kingdom: Cambridge University Press.

Čvorović, A. (2012). The Influence of Basketball on the Asymmetry in the Use of Limbs. Montenegrin Journal of Sports Science and Medicine, 1(1), 15-19.

Gaurav, V., Singh, M., \& Singh, S. (2010). Anthropometric characteristics, somatotyping and body composition of volleyball and basketball players. Journal of Physical Education and Sports Management 1(3), 28-32.

Gusić, M., Popović, S., Molnar, S., Mašanović, B., Radaković, M. (2017). SportSpecific Morphology Profile: Differences in Anthropometric Characteristics among Elite Soccer and Handball Players. Sport Mont Journal, 15(1): 3-6. 
Havelka, N., \& Lazarevic, Lj. (1981). Sport i liènosti. Beograd: Sportska knjiga. Karalejic, M., \& Jakovljevic, S. (2008). Teorija i metodika košarke. Beograd: Fakultet sporta i fizièkog vaspitanja.

Masanovic, B. (2008). Determination of body composition of athletes. Unpublished Master Thesis. Novi Sad: Faculty of Sport and Physical Education.

Masanovic, B. (2009). Differences of anthropometrical status on top leve handball players and non sportsmen. Sport Mont, 6(18-19-20), 569-75.

Masanovic, B. (2015). Anthropological indicators of the proprioceptive training success with football players and students aged 15-16 years. Unpublished Doctoral Dissertation. Novi Sad: University of Novi Sad.

Masanovic, B., \& Vukasevic, V. (2009). Differences of anthropometrical status on basketball and handball players in junior stature. Sport Mont, 6(1819-20), 576-82.

Masanovic, B., Popovic, S. \& Molnar, S. (2009). The differences in some anthropometric characteristics of elite football and basketball players. In Book of Abstracts XLVIII Congress of Anthropological Society of Serbia (87) Prolom Banja: Antrpological Society of Serbia.

Masanovic, B., Popovic, S., \& Bjelica, D. (2018). Comparative Study of Anthropometric Measurement and Body Composition Between Junior Socce and Volleyball Players From National League. In Book of Abstracts 15th International Scientific Conference on Transformation Process in Sport "Sport Performance" (58), Podgorica: Montenegrin Sports Academy.

Masanovic, B., Vukotic, M., Bjelica, D., \& Popovic, S. (2018). Describing Physical Activity Profile of Older Montenegrin Males Using the Internationa Physical Activity Questionnaire (IPAQ). In Book of Abstracts 15th International Scientific Conference on Transformation Process in Sport "Sport Performance" (61), Podgorica: Montenegrin Sports Academy.

Mišigoj-Duraković, M., Matković, B., \& Medved, R. (1995). Morfološka antropometrija u športu. Morphological anthropometry in sports. Zagreb, Croatia: Fakultet za fizičku kulturu.

Nepocatych, S., Balilionis, G., \& O'Neal, E. K. (2017). Analysis of dietary intake and body composition of female athletes over a competitive season. Montenegrin Journal of Sports Science and Medicine, 6(2), 57-65. doi: 10.26773/mjssm.2017.09.008

Nikolaidis, P.T., \& Vassilios-Karydis, N. (2011). Physique and body composition in soccer players across adolescence. Asian J Sports Med, 2(2), 75-82.

Popovic, S. (2016). Body Height and its Estimation Utilizing Arm Span Measurements in Montenegrin Adults: National Survey. In Book of Summaries of 11th FIEP European Congress "Anthropological Aspects of Sport Physical Education and Recreation" (5-6), Banjaluka: University of Banjaluka, Faculty of Physical Education and Sport.

Popovic, S. (2017). Local Geographical Differences in Adult Body Height in Montenegro. Montenegrin Journal of Sports Science and Medicine, 6(1) 81-7.

Popovic, S. (2017). Local Geographical Differences in Adult Body Height in Montenegro. Monten. J Sports Sci Med, 6(1), 81-7.

Popovic, S., Akpinar, S., Jaksic, D., Matic, R., \& Bjelica, D. (2013). Comparative Study of Anthropometric Measurement and Body Composition between Elite Soccer and Basketball Players. International Journal of Morphology, 31(2), 461-7.

Popović, S., Bjelica, D., Georijev, G., Krivokapić, D. \& Milašinović, R. (2017). Body height and its estimation utilizing arm span Measurements in Macedonian. The anthropologis, 24(3), 737-45.

Popović, S., Bjelica, D., Molnar, S. Jakšić, D, \& Akpinar, S. (2013). Body height and its estimation utilizing arm span Measurements in serbian adults. Int. J. Morphol., 31(1), 271-9.

Popović, S., Bjelica, D., Tanase, G., \& Milašinović, R. (2015). Body Height and Arm Span in Bosnian and Herzegovinian Adults, Monten. J. Sports Sci. Med. 4(1), 29-36.
Popovic, S., Bjelica, D., Vukotic, M., \& Masanovic, B. (2018). Describing Physical Activity Profile of Older Montenegrin Females Using the International Physical Activity Questionnaire (IPAQ). In Book of Abstracts 15th International Scientific Conference on Transformation Process in Sport "Sport Performance" (60-61), Podgorica: Montenegrin Sports Academy.

Popovic, S., Masanovic, B., Molnar, S., \& Smajic, M. (2009). Determining Body Composition of Top Level Athletes. Teme, 33(4), 1534-49.

Popovic, S., Molnar, S., \& Masanovic, B. (2010). Differences of some anthropometrical characteristics on young football players and boys who don't do any sport. Journal of Antrpological Society of Serbia, 45, 273-9.

Popovic, S., Smajic, M., Joksimovic, A., \& Masanovic, B. (2010). The differences in body composition between football players of different rank competitions. Sport Mont, 8(23-24), 362-7.

Popovic. S., Bjelica, D., Jaksic, D., \& Hadzic, R. (2014). Comparative Study of Anthropometric Measurement and Body Composition between Elite Soccer and Volleyball Players. International Journal of Morphology, 32(1), 267-74.

Ramos-Campo, D.J., Martinez-Sanchez, F., Esteban-Garcia, P., Rubio-Arias, J.A., Bores, C.A., Clemente-Suarez, V.J., \& Jimenez-Diaz, J.F. (2014). Body Composition Features in Different Playing Position of Professional Team Indoor Players: Basketball, Handball and Futsal. Int. J. Morphol., 32(4), 1316-24.

Saavedra, J. M., porgeirsson, S., Kristjansdottir, H., Halldorsson, K., Guðmundsdottir, M. L., \& Einarsson, I. P. (2018). Comparison of training volumes in different elite sportspersons according to sex, age, and sport practised. Montenegrin Journal of Sports Science and Medicine, 7(2), Ahead of Print. doi: 10.26773/mjssm.180906

Sermaxhaj, S., Popović, S., Bjelica, D., Gardašević, J., \& Arifi, F. (2017). Effect of recuperation with static stretching in isokinetic force of young football players. Journal of Physical Education and Sport, 17(3), 1948-53. doi: 10.7752/jpes.2017.03191

Stojanovic, M., Calleja-Gonzalez, J., Mikic, M., Madic, D., Drid, P., Vučković, I., \& Ostojić, S. (2016). Accuracy and Criterion-Related Validity of the 20-M Shuttle Run Test in Well-Trained Young Basketball Players. Montenegrin Journal of Sports Science and Medicine, 5(2), 5-10.

Strel, J. (2006). Correlation of physical characteristics and general endurance: A comparison of 7- to 19-year-old pupils between 1983, 1993 and 2003. Anthropological Notebooks 12(2), 113-28.

Vasiljević, I., Bjelica, D., Popović, S., \& Gardašević, J. (2015). Analysis of nutrition of preschool-age and younger school-age boys and girls. Journal of Physical Education and Sport, 15(3), $426-8$.

Vukasevic, V. (2010). Uporedna analiza morfoloških i motorièkih dimenzija košarkaša prvog i drugog ranga takmièenja srbije i crne gore. Neobjavljena magistarska teza. Beograd: ,'Alfa" BK Univerzitet, Fakultet za menadžment u sportu.

Vukotic, M. (2010). Nivo morfoloških karakteristika, motoričkih i funkcionalnih sposobnosti sportista različitog sportskog usmjerenja. Neobjavljena magistarska teza. Nikšić: Fakultet za sport i fizičko vaspitanje.

Vukotic, M. (2011). Differences of anthropometric characteristic and motor abilities of different sport orientation. Sport Mont, 9(28-29-30), 112-8.

Vukotic, M. (2018). Comparative analysis of antropmtric indicators of sportisis of different soprts guidance. In Book of Abstracts 15th International Scientific Conference on Transformation Process in Sport "Sport Performance" (75-76), Podgorica: Montenegrin Sports Academy.

Vukotic, M., Čorluka, M., Vasiljević, I., \& Bubanja, M. (2018). Differences in the Morphological Characteristics and Body Composition of Handball Players WHC Levalea in Montenegro and WHC Grude in Bosnia and Herzegovina. J. Anthr. Sport Phys. Educ. 2(2018) 2: 49-53 Original scientific paper DOI: 10.26773/jaspe.180409 